\title{
Implicações dos repasses constitucionais na qualidade da educação municipal das regiões Norte e Nordeste do Brasil
}

\author{
Joyce Santana Bernardo ${ }^{1}$ \\ ORCID: 0000-0003-0014-8964 \\ Luiz Antônio Abrantes ${ }^{1}$ \\ ORCID: 0000-0002-4460-125X \\ Fernanda Maria de Almeida ${ }^{1}$ \\ ORCID: 0000-0001-9132-1552 \\ Cristiana Tristão Rodrigues ${ }^{1}$ \\ ORCID: 0000-0001-6639-969X
}

\section{Resumo}

A educação é direito de todos, sendo papel do Estado garanti-la com qualidade, ainda que os parâmetros de qualidade sejam diferentes para os indivíduos. Para assegurar que os recursos sejam destinados a atividades educacionais, a Constituição Federal brasileira de 1988 determina percentuais mínimos de aplicação, assim como os fundos de manutenção do ensino, como o vigente Fundo de Manutenção e Desenvolvimento da Educação Básica (Fundeb). Portanto, este estudo verificou a influência de transferências intergovernamentais, enquanto característica financeira dos municípios, e dos valores repassados ao Fundeb, na qualidade da educação dos municípios das regiões brasileiras Norte e Nordeste. Assim, utilizou-se de modelo de regressão com dados em painel, para o período de 2007 a 2013, cujos resultados indicaram que a maioria das transferências intergovernamentais recebidas pelos municípios impactaram positivamente no desenvolvimento educacional. Além disso, destacou-se a importância dos recursos do Fundeb, ainda que com magnitude baixa. Entretanto, o ponto mais importante refere-se à contribuição expressiva do fato de o município receber a complementação financeira da União no Fundo, indicando que a premissa de minimizar as diversidades regionais através deste recurso tenha sido efetiva. Desse modo, a complementação financeira da União feita ao Fundeb foi de grande valia para equalizar as destoantes divergências existentes no setor educacional.

\section{Palavras-chave}

Educação - Fundeb - Transferências intergovernamentais.

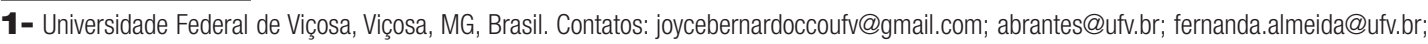
cristiana.rodrigues@ufv.br. 


\section{Implications of constitutional transfers on the quality of municipal education in the North and Northeast of Brazil}

\section{Abstract}

The right to education is for all, and it is the role of the state to guarantee it with quality, even though the quality parameters are different for each individual. The Brazilian Federal Constitution of 1988 determines minimum application percentages to ensure public resources to educational activities. It also provides resources to be used in education maintenance, such as the current Fund for Maintenance and Development of Basic Education (Fundeb). In this context, this study aimed to verify the influence of intergovernmental transfers and the values passed on to Fundeb on the education quality of municipalities of the North and Northeast regions of Brazil. A panel data regression model was used for the period 2007-2013. The results indicated that most intergovernmental transfers received by municipalities were positively related to educational development. In addition, there was a small but positive influence of Fundeb resources on the quality of education. However, the most important point was the significant contribution of the financial complement received by the Brazilian municipalities granted by the Fund. This result highlights the crucial assumption of minimizing regional diversity through this financial resource. Thus, the federal government's financial complementation to Fundeb was important to equalize the divergences in the educational sector.

\section{Keywords}

Education - Fundeb - Intergovernmental transfers.

\section{Introdução}

A educação brasileira é definida como direito social pela Constituição Federal de 1988 (CF/88) no artigo 6º e reforçada pelo artigo 205 que preza por padrão mínimo de qualidade do ensino público, cujo conceito ainda não está definido de forma clara na literatura (CURY; FERREIRA; AMPID, 2009; ARAÚJO, 2012), mas podendo ser associado a notas obtidas em provas de desempenho aplicadas em âmbito nacional.

Para aprofundar nas questões educacionais, foi instituída a Lei de Diretrizes e Bases da Educação (LDB), pela lei no 9.394/96, segundo a qual o acesso ao ensino básico "é direito público subjetivo, podendo qualquer cidadão, grupo de cidadãos, associação comunitária, organização sindical, entidade de classe ou outra legalmente constituída e, ainda, o Ministério Público, acionar o poder público para exigi-lo" (BRASIL, 1996, art. 5º). 0 ensino básico compreende a educação infantil, ensino fundamental, médio, educação de jovens e adultos (EJA) e educação especial. Ademais, esse dispositivo legal aborda os 
princípios que devem ser observados para ministrar o ensino, a organização da educação nacional com as competências de cada ente federado, e os níveis de ensino.

No tocante ao financiamento das atividades educacionais, o art. 68 da LDB descreve a composição dos recursos destinados ao ensino, a exemplo da receita própria de impostos, das transferências constitucionais, da receita do salário-educação e de outras contribuições sociais, da receita de incentivos fiscais, dentre outros (BRASIL, 1996). Ademais, reforça as obrigações previstas pelo artigo 212 da CF/88, cabendo à União aplicar 18\% e os estados, Distrito Federal e municípios, o mínimo de $25 \%$ na educação.

Assim, com o intuito de garantir que os recursos sejam efetivamente aplicados nas atividades de educação, surgiram fundos de natureza contábil, como o Fundo de Manutenção e Desenvolvimento do Ensino Fundamental e de Valorização do Magistério (Fundef) e Fundo de Manutenção e Desenvolvimento da Educação Básica (Fundeb). 0 primeiro vigorou de 1998 a 2006, sendo exclusivamente para atendimento ao ensino fundamental (DAVIES, 2006), o que se tornou a principal crítica e justificativa para elaboração de uma política mais ampliada, o Fundeb, que está em vigência desde 2007 (BRASIL. FUNDEB, 2008). A principal vertente deste está na premissa de redução das desigualdades regionais, pois a complementação financeira realizada pela União garante que todos terão acesso ao valor mínimo anual estipulado por aluno por segmento de ensino (PINTO, 2014).

Tais fundos podem ser compreendidos como políticas públicas (SECCHI, 2013; HOWLETT; RAMESH; PERL, 2013), pois visam ao acesso igualitário ao ensino de forma eficiente quanto à aplicação de recursos, além de minimizar as disparidades regionais (PINTO, 2014). Ou seja, “compreendem o conjunto das decisões e ações relativas à alocação imperativa de valores envolvendo bens públicos” (RUA, 1998, p. 232). Especialmente nas regiões Norte e Nordeste do Brasil, há alto grau de municipalização, arcando com responsabilidade maior quanto à educação que os demais entes federados (ARAÚJO, 2012; PINTO, 2014). Aliado à baixa capacidade de arrecadação de receitas próprias e a expressiva dependência no Fundo de Participação dos Municípios (FPM) (PINTO, 2007), tais municípios enfrentam dificuldades para assegurar condições mínimas para os habitantes, precisando recorrer a complementações financeiras, como ocorre na educação.

Sob essa ótica, Campos e Cruz (2009) analisaram o potencial do Fundeb como meio de aperfeiçoar o ensino básico público de municípios cariocas. Os autores indicam que o Fundo não é capaz de assegurar aos municípios com baixos indicadores de desempenho educacional o montante de recursos necessários para o desenvolvimento da educação. Ademais, apontaram que as melhores condições de infraestrutura para atividades educacionais não se associam apenas aos municípios cujo aporte de recursos é maior, reforçando a necessidade de boa gestão destes.

Já Silveira e colaboradores (2017) avaliaram o efeito do Fundeb sobre o desempenho escolar sob três óticas que interferem no desempenho escolar: valorização da remuneração dos professores; profissionais mais bem qualificados; e investimentos em infraestrutura para propiciar melhores condições de oferta do ensino. Os principais achados indicaram que a implementação do Fundo foi efetiva para melhorar o desempenho escolar e a valorização salarial dos professores, que buscam ser cada vez mais qualificados. Além 
disso, como a análise foi para o Brasil, constatou-se que as regiões Norte, Nordeste e Centro-Oeste apresentaram impactos menores que a região Sul, sugerindo que a proposta de redução das desigualdades inter-regionais não foi alcançada pelo Fundo.

Brand (2013), por sua vez, analisou os possíveis impactos socioeducacionais do Fundeb na qualidade do ensino, bem como na valorização dos profissionais da rede pública de um município do norte do Rio Grande do Sul. Por meio de entrevista semiestruturada e dos documentos oficiais, concluiu que não houve significativas alterações na política salarial dos professores, como também não ocorreram avanços quanto à qualidade educacional, medida através do Índice de Desenvolvimento da Educação Básica (Ideb).

Com foco no Norte brasileiro, Leite e colaboradores (2017), avaliaram o impacto do Fundo sobre o desempenho dos alunos da rede pública do estado do Amazonas na disciplina de matemática, sendo esta a variável de desempenho educacional. Os resultados apontaram que o Fundeb não possui efeito sobre a proficiência em matemática, sugerindo que o montante de recursos não é determinante da qualidade educacional. Por outro lado, aspectos como características dos alunos, dos professores e das escolas mostraram-se significantes quanto ao desempenho dos mesmos.

Dessa forma, percebe-se que os estudos que analisaram apenas os recursos financeiros destinados à educação por meio do Fundeb, desconsiderando a estrutura financeira dos municípios. Portanto, o objetivo geral deste estudo consiste em verificar a influência de transferências intergovernamentais, enquanto característica financeira dos municípios, e dos valores repassados ao Fundeb na qualidade educacional dos municípios das regiões brasileiras Norte e Nordeste. Especificamente, pretende-se analisar de modo comparativo a situação de todos os municípios das regiões mencionadas, com o nível arrecadatório e financeiro daqueles que recebem a complementação financeira da União ao Fundeb, indicando baixa capacidade arrecadatória e, por fim, com o quadro financeiro daqueles que não necessitam de complementações para alcançar o valor mínimo anual per capita estipulado.

A justificativa para a realização deste trabalho consiste em reforçar as dificuldades encontradas por municípios de pequeno porte em obter receitas próprias, ficando dependentes das transferências intergovernamentais. Tal restrição dificulta a aplicação dos recursos necessários para prover educação de qualidade, bem como desenvolvimento econômico municipal. Assim, entender esses aspectos pode contribuir para que ocorram avanços educacionais efetivos.

\section{Educação, manutenção e desenvolvimento}

\section{Estrutura do sistema educacional brasileiro}

0 ensino básico público de qualidade é direito garantido a todos os brasileiros conforme o inciso VII do artigo 206 da CF/88. De modo a assegurar a ocorrência deste direito, o artigo 211 da $\mathrm{CF} / 88$ dispõe sobre a organização em regime de colaboração ao ensino por parte da União, dos estados e dos municípios. Assim, compete aos estados e o Distrito Federal o atendimento ao ensino fundamental (do $1^{\circ}$ ao $9^{\circ}$ ano) e o ensino médio (de $1^{\circ}$ a $3^{\circ}$ ano). Os municípios devem atuar com a maior atenção no ensino infantil 
(creche e pré-escola), mas também se responsabilizam pelo ensino fundamental. Já o Governo Federal responde pela organização do

[...] sistema federal de ensino e o dos Territórios, financiará as instituições de ensino públicas federais e exercerá, em matéria educacional, função redistributiva e supletiva, de forma a garantir equalização de oportunidades educacionais e padrão mínimo de qualidade do ensino mediante assistência técnica e financeira aos Estados, ao Distrito Federal e aos Municípios (BRASIL, 1988, art. $\left.211^{\circ}, \S 1^{\circ}\right)$.

A Lei de Diretrizes e Bases da Educação também reforça que o ensino deve atender a "padrões mínimos de qualidade de ensino, definidos como a variedade e quantidade mínimas, por aluno, de insumos indispensáveis ao desenvolvimento do processo de ensino aprendizagem" (BRASIL, 1996, artigo 4º inciso IX). Entretanto, o conceito de qualidade educacional é polissêmico na literatura dadas as diferentes referências que possuem (JOHANNESSEN, 2006).

Para Oliveira e Araújo (2005), esse conceito está atrelado a duas noções de eficiência: serviço de alta qualidade sendo ofertado que possui destaque no setor, ou serviço de média ou baixa qualidade com custo mínimo para os governos. Entretanto, para que sejam avaliadas as políticas implementadas e o desempenho dos alunos e das escolas no Brasil, utiliza-se de um conjunto de provas padronizadas aplicadas em escala nacional com o intuito de mensurar a qualidade do ensino, como o Sistema de Avaliação da Educação Básica (Saeb) (BRASIL; INEP, s. d.a) instituído em 1990, cujo principal objetivo é "realizar um diagnóstico da educação básica brasileira e de alguns fatores que possam interferir no desempenho do estudante, fornecendo um indicativo sobre a qualidade do ensino ofertado" (BRASIL. INEP, 2017).

Dentre esses testes está a Prova Brasil (BRASIL. MEC, s. d.) aplicada para a quarta e oitava séries do ensino fundamental, abrangendo questões de português e matemática e um questionário socioeconômico para compreender o contexto dos estudantes. Concomitantemente, são analisados aspectos demográficos e profissionais dos professores e diretores das escolas. Todas estas informações são repassadas ao Ministério da Educação (MEC) e às Secretarias de Educação para subsidiar as decisões quanto às ações a serem desenvolvidas visando minimizar as distorções e fragilidades do sistema educacional (BRASIL. MEC, 2017). Já no ensino médio, é considerado como parâmetro de avaliação da qualidade do ensino o Exame Nacional do Ensino Médio (Enem) (BRASIL; INEP, s. d.b), o qual avalia os estudantes nas dimensões de ciência humanas; ciências da natureza; linguagens e códigos; matemática; e redação. Além disso, esse exame é considerado atualmente a principal forma de ingresso no ensino superior (BRASIL. INEP, 2017).

\section{Transferências constitucionais aos municípios}

São diversas as modalidades de transferências intergovernamentais, cujo objetivo principal é garantir "o equilíbrio fiscal quanto para a qualidade da intervenção do setor público na economia” (MENDES; MIRANDA; COSIO, 2008, p. 7). Nesse sentido, dadas 
as distorções de arrecadação própria dos municípios de pequeno porte, foi instituído o Fundo de Participação dos Municípios (FPM), pela Lei $n^{\circ} 5.172$, de 25 de outubro de 1966. A composição do fundo é de 22,5\% do montante arrecado com o Imposto de Renda (IR) e o Imposto sobre Produtos Industrializados (IPI), além de 1\% definido pela Emenda Constitucional $n^{\circ} 55$ de 2007. A sua forma de distribuição é inversamente proporcional ao número de habitantes, dada a premissa de que os municípios de grande porte possuem maior capacidade de arrecadação própria.

Percebe-se, portanto, que a política de fundos tem como objetivo principal minimizar as desigualdades existentes entre os municípios e regiões, tentando alçar incentivos financeiros naquelas localidades com baixos índices de desenvolvimento econômico e humano. Dentre as políticas afetadas pelos baixos níveis orçamentários disponíveis estão as educacionais com o objetivo de reduzir as disparidades regionais. 0 Fundeb se mostra como mecanismo interessante para atender a esse objetivo, principalmente por meio da complementação financeira feita pela União, para que os valores mínimos anuais por aluno sejam cumpridos nos estados que não conseguem alcançá-los, tais como os do Norte e Nordeste brasileiro.

\section{Transferências constitucionais à educação e fundos de manutenção do ensino}

Os entes federativos devem destinar mínimos constitucionais para financiar a educação (BRASIL, 1988, art. 212), os quais são obtidos pela arrecadação de receitas próprias e transferências constitucionais. Dada a diversidade na arrecadação tributária, a destinação para a educação também pode ser diferente. Assim, para promover educação mais igualitária permaneceu vigente, de 1998 a 2006, o Fundo de Manutenção e Desenvolvimento do Ensino Fundamental e de Valorização do Magistério (Fundef), "constituído por 15\% (60\% de 25\%) da receita proveniente dos seguintes impostos e transferências: ICMS, IPI/Exportação, FPE, FPM e compensação financeira da LC n 87/96 (Lei Kandir)" (CALLEGARI, 2010, p. 39). Entretanto, ainda que tenha contribuído em alguns aspectos para a educação (CAMPOS; CRUZ, 2009; BANDEIRA, 2013), esse fundo proporcionava melhorias apenas para a educação fundamental, excluindo outros níveis de ensino.

Desse modo, criou-se o Fundo de Manutenção e Desenvolvimento da Educação Básica (Fundeb), um fundo de transferência de recursos para as atividades educacionais, de natureza contábil e formado pelos 26 estados da federação e o Distrito Federal. Regulamentado pela Lei $n^{\circ} 11.494 / 2007$, tem como intuito assegurar que existam recursos suficientes para os alunos do nível básico em geral, seja na zona rural ou urbana.

Para realizar a distribuição dos recursos aos fundos contábeis são consideradas as matrículas de alunos em cada modalidade de ensino, respeitando o valor mínimo anual por aluno, que "representa o mínimo per capita a ser assegurado no ano, de forma que os recursos da complementação da União sejam repassados aos entes governamentais localizados no estado cujo valor por aluno/ano seja inferior a esse mínimo" (BRASIL. FUNDEB, 2008, p. 15). 
Os coeficientes para distribuição dos recursos variam conforme a modalidade de ensino, localidade de atuação, regularidade do ensino, entre outros. Os anos iniciais do ensino fundamental urbano (Tabela 1) são a referência para o cálculo das transferências, sendo igual a 1 (um). A pré-escola em tempo integral, por exemplo, indica que eram necessários 15\% a mais de recursos para garantir o valor mínimo anual para os alunos. Por outro lado, nas creches públicas em tempo parcial eram necessários apenas 80\% dos recursos totais de referência.

Tabela 1- Coeficientes de distribuição dos recursos do Fundeb

\begin{tabular}{ccc}
\hline Segmentos da educação básica considerados & Fatores de ponderação para 2008 \\
\hline Creche pública em tempo integral & 1,10 \\
\hline Creche pública em tempo parcial & 0,80 \\
\hline Pré-escola em tempo integral & 1,15 \\
\hline Pré-escola em tempo parcial & \multirow{2}{*}{0,90} \\
\hline Anos iniciais do ensino fundamental urbano & \multirow{2}{*}{1,00} \\
\hline Anos iniciais do ensino fundamental no campo & 1,05 \\
\hline Anos finais do ensino fundamental urbano & 1,10 \\
\hline Anos finais do ensino fundamental no campo & 1,15 \\
\hline Ensino fundamental em tempo integral & 1,25 \\
\hline Ensino médio urbano & 1,20 \\
\hline Ensino médio no campo & 1,25 \\
\hline Ensino médio em tempo integral & 1,30 \\
\hline Ensino médio integrado à educação profissional & 1,30 \\
\hline
\end{tabular}

Fonte: adaptado de Manual do Fundeb (BRASIL, 2008).

Os recursos recebidos através do Fundeb devem ser empregados exclusivamente em ações de manutenção e de desenvolvimento da educação básica pública, particularmente na valorização do magistério, devendo ser subdivididos para aplicação, sendo 60\% para remuneração dos profissionais em efetivo exercício da educação básica, considerando todos os encargos envolvidos; e 40\% em despesas diversas consideradas como de Manutenção e Desenvolvimento do Ensino (MDE), realizadas na educação básica.

Caso um município não atenda aos limites impostos pela legislação, podem ocorrer punições no momento das prestações de contas junto ao Conselho de Acompanhamento e Controle Social do Fundeb, cuja "atuação deve ser pautada no interesse público, buscando o aprimoramento da relação formal e contínua com a administração pública local, 
responsável pela gestão e aplicação dos recursos do Fundo, para que o acompanhamento seja efetivo" (BRASIL. FUNDEB, 2008, p. 30).

Ainda que relativamente pequeno, um dos avanços do Fundeb em relação do Fundef refere-se ao aumento do percentual de 15\% para 20\%, calculado sobre as seguintes fontes de impostos e de transferências constitucionais: Fundo de Participação dos Estados (FPE); Fundo de Participação dos Municípios (FPM); Imposto sobre Produtos Industrializados, proporcional às exportações (IPI-Exp); Imposto sobre Circulação de Mercadorias e sobre prestação de Serviços (ICMS); Imposto sobre a Propriedade de Veículos Automotores (IPVA); Imposto sobre a Propriedade Territorial Rural (cota-parte dos municípios) (ITRm); Imposto sobre Transmissão Causa Mortis e doações de quaisquer bens ou direitos (ITCMD); recursos relativos à desoneração de exportações de que trata a LC no 87/96 (Lei Kandir); cotas-partes, receita da dívida ativa tributária, além dos juros e multas referentes aos itens supracitados (BRASIL. FUNDEB, 2008; CAMPOS; CRUZ, 2009).

Com vistas a diminuir as desigualdades, o Fundo apresenta uma fragilidade, pois não traz novos recursos significativos para a educação, uma vez que sua principal função é a redistribuição dos recursos já vinculados às atividades educacionais, "o que significa que uns governos ganharão, mas outros perderão na mesma proporção, sobretudo quando não houver complementação federal, que será o único recurso novo para o sistema educacional como um todo, que não é tão significativo assim" (DAVIES, 2006, p. 763).

Entretanto, Pinto (2014) ressalta com base em Bremaeker (2011 apud PINTO, 2014) que essa política de fundos educacionais prejudica os municípios de pequeno porte e com baixa capacidade de arrecadação própria, visto que os valores a serem repassados são proporcionais ao número de alunos matriculados. Ou seja, aqueles municípios cuja população é pequena, obterão arrecadação menor tanto de tributos vinculados ao consumo e à renda, assim como terão número menor de alunos matriculados nas escolas. Para atender às diversas legislações acerca de infraestrutura e de pessoal nas instituições de ensino básico, os municípios provavelmente apresentarão algumas dificuldades quanto à execução das normas, principalmente quanto ao aspecto financeiro. Dessa forma, seria interessante que a base para distribuição dos recursos do Fundeb levasse em consideração essas externalidades.

\section{Complementação da União ao Fundeb}

Nos casos em que os municípios não conseguem alcançar o valor mínimo por aluno de cada segmento, cabe à União realizar a complementação financeira, a fim de reduzir as desigualdades decorrentes, principalmente, de fatores regionais e institucionais. Assim, conforme Davies (2006, p. 770) esse é um dos casos em que o município se beneficia dos recursos advindos do Fundeb, pois, para o autor, só se torna benéfico receber os recursos deste programa em duas situações: "(1) para os governos que contribuam para os fundos proporcionalmente menos do que os outros e cujas matrículas sejam proporcionalmente maiores do que as dos demais governos no âmbito estadual e/ou (2) para os governos que recebem a complementação".

De forma empírica, Pinto (2014) percebeu que a complementação financeira da União é importante para os municípios, reduzindo o desvio padrão referente aos valores médios 
recebidos por aluno de 25\% para 13\%, bem como uma amplitude entre os maiores e menores valores de 2,88 para 1,45 . Os estados cujos municípios recebem esse reforço financeiro federal estão, em sua maioria, nos estados do Alagoas, Amazonas, Bahia, Ceará, Maranhão, Pará, Paraíba, Pernambuco e Piauí, conforme os dados disponibilizados pela prestação de contas municipais na página eletrônica da Secretaria do Tesouro Nacional (STN).

Silveira e colaboradores (2017) argumentam que essa complementação é importante na tentativa de minimizar as desigualdades regionais, pois apenas aqueles municípios com dificuldade de arrecadação terão esta contribuição, não os distanciando dos demais municípios, pois o valor mínimo anual por aluno proposto, ao menos, será atendido. Essa importância pode ser percebida na proporção de valores anuais realizados de complementação financeira desde a implementação do Fundo, cujo percentual, em 2007, foi de apenas 2,60\%, passando para 17,04\% em 2016.

\section{Procedimentos metodológicos}

\section{Caracterização da pesquisa}

Este estudo é descritivo, com abordagem quantitativa e visa a analisar os efeitos da complementação financeira da União ao Fundeb e de aspectos financeiros dos municípios brasileiros no indicador de qualidade educacional Índice Firjan de Desenvolvimento Municipal - Educação (IFDM-Educação).

Constituem-se como objeto de análise os municípios brasileiros das regiões Norte (450) e Nordeste (1.794). Estas regiões representavam 5,33\% e 13,93\% do Produto Interno Bruto brasileiro de 2014, respectivamente, indicando o baixo potencial produtivo se comparado à região Sudeste (54,94\%) e Sul (16,41\%) (BRASIL. IBGE, 2017). Devido à atratividade turística nordestina e os avanços de infraestrutura realizados pelas gestões municipais e estaduais, percebe-se que o PIB bruto do Nordeste é maior que a região Norte, ainda que nesta exista uma zona industrial (Zona Franca de Manaus).

Quanto ao desenvolvimento dessas regiões, observa-se um nível médio, com base no valor do Índice de Desenvolvimento Humano Municipal (IDHM) do ano de 2010, de 0,674 pontos. Destacam-se como estados com alto desenvolvimento humano Mato Grosso $(0,725)$ e Amapá $(0,708)$. Por outro lado, os estados do Maranhão $(0,639)$ e Alagoas $(0,631)$ apresentam-se com baixos níveis de desenvolvimento humano, se comparados ao nível médio do país de 0,705 (PNUD, 2017).

\section{Variáveis e operacionalização da pesquisa}

Conforme a Tabela 2, o Índice Firjan de Desenvolvimento Municipal na dimensão Educação (IFDM-Educação) é a variável dependente, calculada pelo Sistema Firjan por meio de seis indicadores disponibilizados pelo Instituto Nacional de Estudos e Pesquisas Educacionais Anísio Teixeira (Inep): o número de matrículas na educação infantil, abandono no ensino fundamental, distorção idade-série no ensino fundamental, docentes com ensino superior no ensino fundamental, média de horas aula diárias no ensino fundamental e o resultado do Ideb no ensino fundamental. A interpretação dos seus valores 
indica que o município possui alto desenvolvimento (0,8 a 1), desenvolvimento moderado $(0,6$ a 0,8$)$, desenvolvimento regular $(0,4$ a 0,6$)$ ou baixo desenvolvimento municipal (0 a 0,4) (IFDM, 2015). Esta variável representa uma proxy da qualidade educacional dos municípios brasileiros, por conseguir contemplar aspectos relacionados ao desempenho escolar dos estudantes, bem como a estrutura escolar indicada pelas taxas de rendimento e capacitação dos professores.

Tabela 2 - Variáveis da pesquisa

\begin{tabular}{|c|c|c|c|}
\hline Dimensão & Variável & Significado & Expectativa \\
\hline & IFDM-Educação & $\begin{array}{l}\text { Índice que demonstra a qualidade da } \\
\text { educação, variando de } 0 \text { a } 1\end{array}$ & - \\
\hline PIB & PIB per capita & $\begin{array}{l}\text { PIB gerado pelo município dividido pela } \\
\text { população total }\end{array}$ & Positiva \\
\hline Fundeb & Fundeb per capita & $\begin{array}{l}\text { Valor total de transferências do Fundeb } \\
\text { dividido pelo número de matrículas }\end{array}$ & Positiva \\
\hline Complementação & $\begin{array}{l}\text { Complementação financeira da União ao } \\
\text { Fundeb }\end{array}$ & $\begin{array}{l}\text { Dummy que indica se o município } \\
\text { recebeu a complementação financeira } \\
\text { (1) ou não (0) }\end{array}$ & Positiva \\
\hline \multirow{8}{*}{ Transferências } & Cota FPM per capita & \multirow{8}{*}{$\begin{array}{l}\text { Valor do tributo recebido pelo município } \\
\text { dividido pela população total }\end{array}$} & Negativa \\
\hline & Cota ITR per capita & & Negativa \\
\hline & Cota Lei Kandir per capita & & Negativa \\
\hline & Cota Petróleo per capita & & Negativa \\
\hline & Cota ICMS per capita & & Negativa \\
\hline & Cota IPVA per capita & & Negativa \\
\hline & Cota IPI-Exportação per capita & & Negativa \\
\hline & Cota Cide per capita & & Negativa \\
\hline \multirow{3}{*}{ Educacional } & Abandono no ensino fundamental & \multirow{2}{*}{$\begin{array}{l}\text { Taxa que representa o nível de abandono } \\
\text { escolar nos municípios }\end{array}$} & Negativa \\
\hline & Abandono no ensino médio & & Negativa \\
\hline & Taxa Distorção Idade-Série (TDI) & $\begin{array}{l}\text { Proporção de alunos com mais de dois } \\
\text { anos de atraso escolar, variando de } 0 \text { a } 1\end{array}$ & Negativa \\
\hline
\end{tabular}

Fonte: elaboração própria.

Partindo da premissa de que municípios com maior capacidade arrecadatória terão bom desempenho quanto ao desenvolvimento, utilizou-se o Produto Interno Bruto (PIB) para indicar o crescimento econômico e, por outro lado, aqueles que não possuem boa estrutura financeira, são mais dependentes das transferências intergovernamentais, representadas pelas cotas recebidas do Fundo de Participação dos Municípios (FPM), do Imposto Territorial Rural (ITR), da Lei Kandir (LC n 87/96), do Imposto sobre Circulação de Mercadorias e Serviços (ICMS), do Imposto sobre Propriedade de Veículos e Automotores (IPVA), do Imposto sobre Produtos Industrializados de exportação (IPI-Exportação), da Cota Petróleo, além da cota de Contribuições de Intervenção no Domínio Econômico (Cide). 
Especificamente no campo educacional, a taxa de distorção idade-série e os níveis de aprovação nos ensinos fundamental e médio são variáveis importantes para explicar os fatores que influenciam o nível de qualidade da educação, visto que podem afetar o modo como as políticas educacionais serão executadas.

Como existem informações referentes aos anos de 2007 a 2013 de vários municípios, atrelado ao objetivo de buscar verificar o efeito de um conjunto de variáveis no IFDMEducação, optou-se pela Regressão de Dados em Painel, dada a maior precisão na estimativa (CAMERON; TRIVEDI, 2005; FÁVERO, 2014) fornecida por esta se comparada ao modelo pool, que considera a observação apenas para um período de tempo ou, de apenas uma unidade de análise para vários tempos.

Outro aspecto interessante do método adotado consiste na estimação mais consistente por meio modelo de efeitos fixos (EF), que contempla observações de vários municípios $(i)$ para vários períodos de tempo $(t)$ e, ainda permite identificar a heterogeneidade individual não observada, e a sua correlação com as demais variáveis (CAMERON; TRIVEDI, 2005), aumentando a capacidade de descrição e previsão se comparado ao modelo pool. Dessa forma, torna-se possível verificar "os efeitos gerados por conta de diferenças existentes entre cada observação” (FÁVERO, 2014, p. 223). Há também a possibilidade de realizar a estimação por meio dos efeitos aleatórios (EA), que indicam que a heterogeneidade não observada é distribuída independentemente dos regressores do modelo, sendo aditivos e invariantes no tempo (CAMERON; TRIVEDI, 2005).

Para verificar qual modelo é mais apropriado ( $p o o l$, EF ou EA), utilizam-se de testes estatísticos que indicam a melhor estimação. Desse modo, para decidir entre o modelo pool e EF, realiza-se o teste de Chow, apresentado de forma conjunta com a estimação deste. A hipótese nula do teste indica que "há igualdade de interceptos e inclinações para todos os municípios” (FÁVER0, 2014, p. 234), a qual em caso de rejeição, permite concluir que a estimação mais adequada é a de efeitos fixos. Por outro lado, para determinar se será mais adequado EA, o teste de Hausman é realizado sob a hipótese nula de que "os efeitos individuais são aleatórios", indicando se "os estimadores são similares (efeitos aleatórios) ou divergem entre si (efeitos fixos) para cada indivíduo” (FÁVERO, 2014, p. 235).

Isso posto, a equação de regressão geral do modelo resume-se na Função 1:

$$
\begin{aligned}
I_{F D} \widehat{M-E d u c} c_{i t}= & \alpha+\beta_{i} \sum_{1}^{8} \text { LNTransferências }_{i t}+\beta_{9} L_{N P I B_{i t}}+\beta_{10} \text { LNFUNDEB }_{i t}+ \\
& \beta_{11} \text { Complementação }_{i t}+\beta_{i} \sum_{1}^{3} \text { Educacional }_{i t}
\end{aligned}
$$

\section{Análise e discussão dos resultados}

\section{Estatísticas descritivas}

A Tabela 3 permite a comparação dos dados para todos os municípios das regiões Norte e Nordeste, além de obter um quadro mais preciso daqueles que recebem a complementação financeira da União (indicando a baixa capacidade arrecadatória) e aqueles que não recebem. 
Quanto à qualidade educacional, os que não recebem a complementação financeira da União apresentaram melhores resultados (IFDM-Educação, taxa de distorção idadesérie e taxa de abandono no ensino fundamental), sendo indicativo de estrutura mais adequada, a qual possibilita maior eficiência no processo de ensino. Exceto pela taxa de abandono no ensino médio, os municípios que receberam a complementação financeira apresentaram médias inferiores aos demais. Tal fato pode estar associado às escolhas dos indivíduos, naquele momento, por recursos financeiros, sem levar em consideração a valorização que obteriam caso estudassem por mais tempo (OLIVEIRA, 2015).

Os indivíduos tendem a escolher o que será mais vantajoso financeiramente, analisando alguns parâmetros para tomar essa decisão. Dentre esses, pode-se elencar a estrutura familiar e a oportunidade de emprego. Ora, se em um município existem muitas oportunidades de exercer funções que não exigem altos níveis de escolaridade, como a agricultura, aliado à dificuldade de muitas famílias quanto à obtenção de rendas, torna-se interessante que o mesmo comece a trabalhar rapidamente. Entretanto, muitas atividades laborais exigem habilidades físicas que serão encontradas com mais facilidade em jovens entre 15 e 18 anos, faixa etária no ensino médio, justificando a média mais normalizada entre os municípios.

Do total de municípios nortistas e nordestinos, 82,34\% receberam a complementação financeira da União no Fundeb, com capacidade produtiva e arrecadatória inferior aos demais, conforme os valores médios do PIB per capita e transferências constitucionais. De modo geral, esses municípios tiveram PIB per capita de $\mathrm{R} \$ 2.877,41$ (33,66\% inferior daqueles que não recebem a complementação), e recebem cerca de $\mathrm{R} \$ 468,60$ por habitante em transferências intergovernamentais.

Tabela 3 - Estatística descritiva para os municípios das regiões Norte e Nordeste: geral, com e sem complementação financeira da União

\begin{tabular}{|c|c|c|c|c|c|c|c|c|c|}
\hline \multirow[b]{2}{*}{ Variáveis } & \multicolumn{3}{|c|}{ Geral } & \multicolumn{3}{|c|}{ Com complementação } & \multicolumn{3}{|c|}{ Sem complementação } \\
\hline & M1 & Min1 & Max1 & M2 & Min2 & Max2 & M3 & Min3 & Max3 \\
\hline IFDM-Educação & 0,5678 & 0 & 0,9255 & 0,5594 & 0 & 0,9255 & 0,6070 & 0,2516 & 0,9002 \\
\hline TDI & 0,4144 & 0 & 0,8425 & 0,4215 & 0 & 0,8425 & 0,3809 & 0,1255 & 0,7785 \\
\hline Complementação & 0,8234 & 0 & 1 & - & - & - & - & - & - \\
\hline PIB per capita & 3135,27 & 1,40 & 413833,80 & 2877,41 & 2,44 & 239495,50 & 4337,42 & 1,40 & 413833,80 \\
\hline FUNDEB per capita & 442,03 & 0,95 & 2346,46 & 434,61 & 0,95 & 1625,32 & 476,21 & 1,12 & 2346,46 \\
\hline Cota FPM per capita & 356,39 & 0,59 & 39939,77 & 341,09 & 0,59 & 3711,26 & 425,66 & 1,24 & 39939,77 \\
\hline Cota ITR per capita & 1,23 & 0,11 & 572,44 & 1,05 & 0,11 & 572,44 & 2,06 & 0,11 & 128,15 \\
\hline Lei Kandir per capita & 6,28 & 0,11 & 486,72 & 5,86 & 0,16 & 122,68 & 8,29 & 0,11 & 486,72 \\
\hline Cota Petróleo per capita & 24,27 & 0,15 & 2128,43 & 25,10 & 0,15 & 346,77 & 20,41 & 0,18 & 2128,43 \\
\hline Cota ICMS per capita & 100,27 & 0,38 & 21278,35 & 87,21 & 0,38 & 5938,49 & 159,34 & 1,00 & 21278,35 \\
\hline Cota IPVA per capita & 5,62 & 0,00 & 1398,98 & 4,94 & 0,00 & 282,98 & 8,69 & 0,11 & 1398,98 \\
\hline Cota IPI-Exportaçãoper capita & 1,45 & 0,00 & 318,58 & 1,43 & 0,00 & 191,29 & 1,62 & 0,11 & 318,58 \\
\hline Cota CIDE per capita & 2,29 & 0,11 & 171,75 & 1,92 & 0,11 & 171,75 & 4,01 & 0,11 & 79,24 \\
\hline Abandono fundamental & 0,0585 & 0 & 0,362 & 0,0609 & 0 & 0,362 & 0,0470 & 0 & 0,261 \\
\hline Abandono médio & 0,1429 & 0 & 1 & 0,1429 & 0 & 1 & 0,1430 & 0 & 0,559 \\
\hline
\end{tabular}

Fonte: dados da pesquisa.

Nota: valores monetários deflacionados com o período de referência igual a dezembro de 2007. 
Com o intuito, ainda, de indicar diferenças no desempenho educacional entre os municípios do Norte e Nordeste que recebem a complementação com aqueles que não recebem, realizou-se um teste de médias simples, com o ano base de 2013. A hipótese nula do teste indica que não existem diferenças entre o desempenho educacional entre os que recebem e os que não recebem a complementação financeira da União no Fundeb. A hipótese alternativa, por sua vez, indica que existem diferenças, sendo que estes possuem desempenho superior daqueles. Com base no p-valor $(0,0000)$ e a 99\% de confiança, constataram-se diferenças no IFDM-Educação entre os municípios, sendo o desempenho superior referente aos não recebem a complementação financeira da União no Fundeb.

\section{Efeitos sobre o desenvolvimento educacional}

Após a estimação dos modelos, realizou-se o teste de Chow (Prob $>\mathrm{F}=0,000$ ), indicando que os modelos mais adequados seriam o de efeitos fixos e, corroborando com tal decisão, o teste de Hausman (Prob>chi2 $=0,000$ ). Sendo assim, a Tabela 4 apresenta as variáveis explicativas e os seus respectivos valores de coeficientes, erro padrão e significância estatística para os modelos 1 (geral), 2 (apenas municípios que receberam a complementação) e 3 (apenas municípios que não receberam a complementação).

Tabela 4 - Resultado das estimações dos modelos

\begin{tabular}{|c|c|c|c|}
\hline Variáveis & Modelo 1 & Modelo 2 & Modelo 3 \\
\hline TDI & $-0,0297(0,0059)^{\star \star \star}$ & $-0,0303(0,0064)^{\star \star \star}$ & $-0,0328(0,0155)^{\star \star}$ \\
\hline Complementação & $0,0067(0,0023)^{\star \star \star}$ & - & - \\
\hline LN PIB per capita & $0,0008(0,0004)^{\star \star}$ & $0,0007(0,0005)$ & $0,0019(0,0007)^{\star *}$ \\
\hline LN FUNDEB per capita & $0,0340(0,0012)^{\star \star \star}$ & $0,0410(0,0013)^{\star \star \star}$ & $0,0313(0,0034)^{\star \star \star}$ \\
\hline LN Cota FPM per capita & $0,0141(0,0015)^{\star \star \star}$ & $0,0173(0,0016)^{\star \star \star}$ & $-0,0018(0,0032)$ \\
\hline LN Cota ITR per capita & $0,0028(0,0006)^{\star \star \star}$ & $0,0030(0,0006)^{\star \star \star}$ & $0,0043(0,0020)^{\star *}$ \\
\hline LN Lei Kandir per capita & $-0,0002(0,0007)$ & $-0,0009(0,0008)$ & $0,0030(0,0017)^{*}$ \\
\hline LN Cota Petróleo per capita & $0,0027(0,0005)^{\star \star \star}$ & $0,0025(0,0005)^{\star \star \star}$ & $0,0037(0,0014)^{\star \star \star}$ \\
\hline LN Cota ICMS per capita & $0,0008(0,0004)^{\star \star}$ & $0,0007(0,0004)$ & $0,0012(0,0011)$ \\
\hline LN Cota IPVA per capita & $0,0050(0,0006)^{\star \star \star}$ & $0,0052(0,0006)^{\star \star \star}$ & $0,0044(0,0017)^{\star \star \star}$ \\
\hline LN Cota IPI-Exportação per capita & $-0,0029(0,0007)^{\star \star \star}$ & $-0,0038(0,0008)^{\star \star \star}$ & $-0,0014(0,0013)$ \\
\hline LN Cota CIDE per capita & $-0,0103(0,0005)^{\star \star \star}$ & $-0,0105(0,0005)^{\star \star \star}$ & $-0,0083(0,0011)^{\star \star \star}$ \\
\hline Abandono Fundamental & $-1,2054(0,0174)^{\star \star \star}$ & $-1,1756(0,0184)^{\star \star \star}$ & $-1,3682(0,0611)^{\star \star \star}$ \\
\hline Abandono Médio & $-0,0391(0,0069)^{\star \star \star}$ & $-0,0395(0,0073)^{\star \star \star}$ & $-0,0644(0,0218)^{\star \star \star}$ \\
\hline Constante & $0,2725(0,0119)^{\star \star \star}$ & $0,2496(0,0131)^{\star \star \star}$ & $0,4614(0,0319)^{\star \star \star}$ \\
\hline $\mathrm{R}^{2}$ between & $54,81 \%$ & $57,70 \%$ & $57,62 \%$ \\
\hline P-valor & 0,0000 & 0,0000 & 0,0000 \\
\hline
\end{tabular}

Fonte: dados da pesquisa.

Nota 1: valores monetários deflacionados com o período de referência igual a dezembro de 2007.

Nota 2: os valores entre parênteses indicam o erro padrão robusto, $e^{*},{ }^{* \star} e^{* \star \star}$ referem-se à significância estatística do coeficiente, sendo 90\%, $95 \%$ e $99 \%$ de confiança, respectivamente. 
De modo geral, os modelos de regressão foram significantes a 99\% de confiança, ou seja, as variáveis selecionadas foram capazes de explicar as variações na qualidade educacional de forma conjunta. Assim, 54,81\% das variações ocorridas no IFDMEducação dos municípios das regiões Norte e Nordeste foram explicadas pelas variações nas variáveis independentes utilizadas, considerando a heterogeneidade existente entre os municípios. Esse percentual de explicação para o modelo 2 foi de 57,70\% e para o modelo 3 foi de 57,62\%.

Quanto às transferências constitucionais recebidas pelos municípios, a maioria dos tributos apresentaram comportamento diferente do esperado, sendo estatisticamente significantes em um dos modelos apresentados. Apenas as variáveis IPI-Exportação e CIDE foram contrárias ao desenvolvimento educacional para os municípios nortistas e nordestinos, bem como para os que receberam a complementação financeira, afetando o IFDM-Educação negativamente. Quanto à CIDE, percebeu-se que o coeficiente de repartição para os municípios de cada estado, em 2013, variou de 0,7348\% (Roraima) a 6,5419\% (Bahia) contra 17,8657\% do estado de São Paulo, por exemplo (BRASIL. STN, 2014).

Por outro lado, quanto mais recursos recebidos pelas demais transferências constitucionais chegaram aos municípios, maior o índice de qualidade da educação. Sob a ótica do consumo, quanto maior a cota de recursos advindos do tributo IPVA, maiores serão os níveis educacionais dos municípios, ou seja, nos municípios em que a população possui capacidade de compra maior, provavelmente terão mais veículos circulando e, consequentemente, a arrecadação de impostos por conta da propriedade do bem.

Especificamente quanto aos recursos advindos da Cota Parte do FPM, não houve significância estatística destes sobre a qualidade educacional quando se analisam apenas os municípios que não receberam a complementação financeira da União. Por outro lado, aqueles que receberam geraram efeitos positivos no IFDM-Educação. Tais achados reforçam a necessidade dos municípios pelas transferências intergovernamentais, os quais são importantes para financiar os itens necessários que garantem o acesso à educação de qualidade. Sob a ótica da redução das desigualdades existentes entre os municípios, o FPM mostrou-se relevante, uma vez que possui significância expressiva para aqueles municípios com baixa capacidade arrecadatória, enquanto torna-se indiferente para aqueles que não receberam a complementação.

No aspecto educacional, o aumento na taxa de distorção série-idade reduziu a qualidade da educação, sendo superior para os municípios que não receberam a complementação financeira da União ao Fundeb. Tal fato indica que quando há alunos matriculados em séries/anos que já deveriam ter sido cursados, não geram contribuições para o desenvolvimento da qualidade educacional. Ora, se o aluno não está conseguindo absorver os conteúdos lecionados, percebidos pelas notas obtidas em provas, provavelmente incorrerá em reprovação ao final do período letivo, sendo comportamento contrário ao avanço da qualidade do ensino.

De forma análoga, o abandono durante o processo de aprendizagem também incorreu em redução na qualidade educacional, sendo mais expressivo para o ensino fundamental. Acredita-se que nesse caso haja interferência expressiva do Programa Bolsa Família (PBF), uma política de redistribuição de rendas, que possui alto percentual de 
beneficiários nos estados do Norte e Nordeste do Brasil. Dentre as condicionalidades para receber os benefícios do PBF, as crianças devem ter frequência escolar mínima de 85\%, o que contribui para a garantia de acesso ao ensino.

Por sua vez, aqueles municípios com alto nível produtivo, representado pelo PIB per capita, aumentaram o nível educacional. As regiões, estados e municípios considerados como mais produtivos tornam-se atrativos para os indivíduos, dada a premissa de que tais locais possuem altas ofertas de emprego, bem como infraestrutura mais avançada. Consequentemente, há o incentivo para a criação e desenvolvimento do capital humano, especialmente quanto ao avanço da escolaridade, pois aqueles que possuem maiores níveis educacionais possuem probabilidade maior de se incorporarem o mercado de trabalho (teoria do capital humano) (ANDRADE, 2010; OLIVEIRA, 2015).

No tocante ao financiamento da educação por meio do Fundeb, quanto maior a aplicação deste recurso, o IFDM-Educação tende a aumentar, reforçando a necessidade que os municípios têm destes para a garantia de educação com qualidade. Especialmente aqueles que receberam a complementação financeira, sofreram impacto maior na qualidade educacional ao receber esse recurso. Esse resultado corrobora com os achados de Silveira et al. (2017), que identificaram avanço no desempenho dos alunos nas provas de matemática conforme os recursos do Fundeb destinados aos municípios. Ademais, como ressaltado por diversos autores (CARVALHO, 2012; BANDEIRA, 2013; BRAND, 2013) o professor exerce influência sobre o processo de aprendizagem do aluno e, como 60\% dos recursos do Fundeb devem ser destinados a remuneração e valorização do magistério, acredita-se que o efeito positivo deste recurso na qualidade educacional seja um efeito indireto, ou seja, com a melhoria das condições de trabalho dos docentes, haverá mais incentivo para garantir que o processo de ensino seja realizado com qualidade, cujo resultado será na qualidade educacional da escola e/ou município.

Os municípios que receberam a complementação financeira da União ao Fundeb foram alguns das regiões Norte e Nordeste do Brasil, os quais compõem este estudo. Logo, o fato de o município receber esse recurso adicional indicou aumentos no nível de qualidade educacional. Ou seja, houve efeito positivo na educação dos municípios do Norte e Nordeste brasileiros que receberam a complementação financeira da União, reforçando a importância deste recurso quanto à minimização das desigualdades regionais existentes no país (OLIVEIRA, 2015; SILVEIRA et al., 2017), visto que a garantia do acesso à educação não se restringirá apenas à capacidade arrecadatória dos entes municipais.

\section{Considerações finais}

0 objetivo geral deste estudo foi verificar se a complementação financeira da União ao Fundo de Manutenção e Desenvolvimento da Educação Básica (Fundeb), analisada enquanto sinalizador da situação arrecadatória dos municípios, aliada a outras características que representam a estrutura financeira dos mesmos, gera algum efeito no nível de qualidade educacional dos municípios da região Norte e Nordeste do Brasil, medido por meio do Índice Firjan de Desenvolvimento Municipal - dimensão Educação. 
Dessa forma, mediante a utilização da metodologia de modelo de regressão com dados em painel com efeitos fixos, percebeu-que a maioria das transferências intergovernamentais recebidas pelos municípios impactam positivamente no desenvolvimento da educação, reforçando o papel principal dos recursos que buscam minimizar as desigualdades regionais existentes, especialmente nos municípios menos desenvolvidos.

Os recursos do Fundeb são importantes para contribuir para o avanço da educação, ainda que de magnitude baixa. Entretanto, o ponto mais importante se refere à contribuição expressiva do fato de o município receber a complementação financeira da União no Fundo, indicando que a premissa de minimizar as diversidades regionais através deste recurso seja efetiva. De forma geral, acredita-se que os recursos em atividades educacionais, especialmente os do Fundeb, podem gerar efeitos indiretos nos indicadores de qualidade educacional, dadas as possíveis melhorias ocasionadas pelos recursos financeiros.

Aos interessados pela temática, sugere-se que sejam analisados os possíveis efeitos dos recursos do Fundeb e da complementação feita pela União em outras dimensões, tais como a geração de emprego, pois, com base na Teoria do Capital Humano, aqueles que possuem nível de escolaridade maior, terão retornos financeiros maiores. Ademais, aqueles que trabalham nas escolas recebem o recurso do Fundeb, que retorna ao mercado dos municípios e estados, contribuindo para o aumento da comercialização, prestação de serviços, dentre outros.

\section{Referências}

ANDRADE, Rita de. Teoria do capital humano e a qualidade da educação nos estados brasileiros. 2010. $75 \mathrm{f}$. Trabalho de Conclusão de Curso (Bacharel em Ciências Econômicas) - Universidade Federal do Rio Grande do Sul, Porto Alegre, 2010.

ARAÚJJ, Raimundo Luiz Silva. Desvendando o perfil dos gastos educacionais dos municípios brasileiros. Educação \& Sociedade, Campinas, v. 33, n. 121, p. 1215-1233, 2012.

BANDEIRA, Dina Carla da Costa. Os impactos do Fundeb na valorização do magistério no município de Magalhães Barata - PA. 2013. 147 f. Dissertação (Mestrado em Educação) - Universidade Federal do Pará, Belém, 2013.

BRAND, Paulo Rogério. Papel do Fundeb na educação pública de um município do norte do RS: impactos na qualidade do ensino e valorização dos profissionais da educação. 2013. 85 f. Dissertação (Mestrado em Educação) - Universidade Regional Integrada do Alto Uruguai e das Missões, Frederico Westphalen, 2013.

BRASIL. Constituição da República Federativa do Brasil de 1988. Brasília, DF: Casa Civil, 1988. Disponível em: $<$ http://www.planalto.gov.br/ccivil_03/constituicao/constituicaocompilado.htm>. Acesso em: 01 set. 2017.

BRASIL. Lei n 9.394, de 20 de Dezembro de 1996. Estabelece as diretrizes e bases da educação nacional. Brasilia, DF: Casa Civil, 1996. Disponível em: <http://www.planalto.gov.br/ccivil_03/leis/L9394.htm>. Acesso em: 01 set. 2017. 
BRASIL. Lei $n^{0}$ 11.494, de 20 de julho de 2007. Regulamenta o Fundo de Manutenção e Desenvolvimento da Educação Básica e de Valorização dos Profissionais da Educação - FUNDEB. Brasília, DF: Casa Civil, 2007. Disponível em: <http://www.planalto.gov.br/ccivil_03/_ato2007-2010/2007/lei//11494.htm>. Acesso em: 01 set. 2017.

BRASIL. FNDE. Fundo Nacional de Desenvolvimento da Educação. FNDE repassa R\$ 888 milhões da complementação da União ao Fundeb. Brasília, DF: FNDE, 2017. Disponível em: <http://www.fnde.gov. br/acesso-a-informacao/institucional/area-de-imprensa/noticias/item/10767-fnde-repassa-r\$-888milh\%C3\%B5es-da-complementa\%C3\%A7\%C3\%A30-da-uni\%C3\%A30-ao-fundeb>. Acesso: 01 set. 2017.

BRASIL. FNDE. Fundo Nacional de Desenvolvimento da Educação. Sobre o Fundeb. Brasília, DF: FNDE, [S. d]. Disponível em: <http://www.fnde.gov.br/financiamento/fundeb/sobre-o-plano-ou-programa/sobre-0fundeb>. Acesso em: 01 set. 2017.

BRASIL. FUNDEB. Manual de orientação. Brasília, DF: Fundeb, 2008. Elaborado por Coordenação-Geral de Operacionalização do Fundeb e de Acompanhamento e Distribuição do Salário-Educação.

BRASIL. IBGE. Instituto Brasileiro de Geografia e Estatística. Produto interno bruto dos municípios. Brasília, DF: IBGE, [s. d.]. Disponível em: <https://sidra.ibge.gov.br/tabela/5938>. Acesso em: 01 de set. 2017.

BRASIL. INEP. Instituto Nacional de Estudos e Pesquisas Educacionais Anísio Teixeira. Conheça o ENEM. Brasília, DF: INEP, [s. d.]b. Disponível em: <http://enem.inep.gov.br/\#/antes?_k=g01umx>. Acesso em: 15 set. 2017.

BRASIL. INEP. Instituto Nacional de Estudos e Pesquisas Educacionais Anísio Teixeira. SAEB. Brasília, DF: INEP, [s. d.]a. Disponível em: <http://portal.inep.gov.br/educacao-basica/saeb>. Acesso em: 15 set. 2017.

BRASIL. MEC. Ministério da Educação. Prova Brasil. Brasília, DF: MEC, [s. d.]. Apresentação. Disponível em: $<$ http://portal.mec.gov.br/prova-brasil>. Acesso em: 15 set. 2017.

BRASIL. STN. Secretaria do Tesouro Nacional. 0 que você precisa saber sobre transferências constitucionais e legais: CIDE-Combustíveis. Brasília, DF: STN, 2014. Disponível em: <http://www.tesouro.fazenda.gov.br/ documents/10180/329483/pge_cartilha_cide-combustiveis.pdf>. Acesso em: 02 dez 2017.

CALLEGARI, Cesar. 0 Fundeb e o financiamento da educação pública no Estado de São Paulo. 5. ed. São Paulo: Aquariana, 2010.

CAMERON, A. Colin; TRIVEDI, Pravin K. Microeconometrics: methods and applications. Cambridge: Cambridge University Press, 2005.

CAMPOS, Bruno Cesar; CRUZ, Breno de Paula Andrade. Impactos do Fundeb sobre a qualidade do ensino básico público: uma análise para os municípios do estado do Rio de Janeiro. Revista de Administração Pública, Rio de Janeiro, v. 43, n. 2, p. 371-393, 2009. 
CARVALHO, Fabricio Aarão Freire. Financiamento da educação: do Fundef ao Fundeb - repercussões da política de fundos na valorização docente da rede estadual de ensino do Pará - 1996 a 2009. 2012. 267 f. Tese (Doutorado em Educação) - Faculdade de Educação, Universidade de São Paulo, São Paulo, 2012.

CRUZ, Cláudia Ferreira et al. Transparência da gestão pública municipal: um estudo a partir dos portais eletrônicos dos maiores municípios brasileiros. Revista de Administração Pública, Rio de Janeiro, v. 46, n. 1, p. 153-76, 2012.

CURY, Carlos Roberto Jamil; FERREIRA, Luiz Antonio Miguel; AMPID. Associação Associação Nacional dos Membros do Ministério Público de Defesa dos Direitos dos Idosos e Pessoas com Deficiência. A judicialização da educação no Brasil. Natal: Ampid, 2009.

DAVIES, Nicholas. Fundeb: a redenção da educação básica? Educação \& Sociedade, Campinas, v. 27, n. 96, p. 753-774, 2006.

FÁVERO, Luiz Paulo et al. Métodos quantitativos com stata: procedimentos, rotinas e análise de resultados. 1. ed. Rio de Janeiro: Elsevier, 2014.

HOWLETT, Michael; RAMESH, M.; PERL, Anthony. Política pública: seus ciclos e subsistemas uma abordagem integradora. Rio de Janeiro: Elsevier, 2013.

IFDM. Índice Firjan de Desenvolvimento Municipal. Leitura do IFDM. [S. I]: IFDM, 2015. Disponível em: <https://www.firjan.com.br/ifdm/consulta-ao-indice/>. Acesso em: 01 de set. 2017.

JOHANNESSEN, Eva Marion. Basic education: also a question of quality. Norway: Save the Children, 2006. Save the Children Norway's Research Fund. Educare, 2006.

LEITE, Felipe Diniz et al. Avaliação do efeito do Fundeb sobre a proficiência em matemática dos alunos do ensino médio no estado do Amazonas. Revista de Estudos Sociais, Cuiabá, v. 9, n. 19, p. 1-17, 2017.

MENDES, Marcos; MIRANDA, Rogério Boueri; COSIO, Fernando Blanco. Transferências intergovernamentais no Brasil: diagnóstico e proposta de reforma. Texto para Discussão da Consultoria Legislativa do Senado Federal, Brasília, DF, n. 40, 2008.

OLIVEIRA, Camila Torres. Financiamento público da educação básica no brasil: uma análise do Fundeb. 2015. Monografia (Bacharelado em Economia) - Universidade de Brasília, Brasília, DF, 2015.

OLIVEIRA, Romualdo Portela de; ARAÚJO, Gilda Cardoso de. Qualidade do ensino: uma nova dimensão da luta pelo direito da educação. Revista Brasileira de Educação, Rio de Janeiro, n. 28, p. 5-23, 2005.

PINTO, José Marcelino de Rezende. A política recente de fundos para o financiamento da educação e seus efeitos no pacto federativo. Educação \& Sociedade, Campinas, v. 28, n. 100, p. 877-897, 2007.

PINTO, José Marcelino de Rezende. Federalismo, descentralização e planejamento da educação: desafios aos municípios. Cadernos de Pesquisa, São Paulo, v. 44, n. 153, p. 624-644, 2014. 
PNUD. Programa das Nações Unidas para o Desenvolvimento. Consulta IDHM. Brasília, DF: PNUD, 2017. Disponível em: <http://www.atlasbrasil.org.br/2013/pt/consulta/>. Acesso em: 01 set. 2017.

RUA, Maria das Graças. Análise de políticas públicas: conceitos básicos. In: RUA, Maria das Graças; CARAVALHO, Maria Izabel Valladão de. 0 estudo da política: temas selecionados. Brasília, DF: Paralelo 15, 1998. p. 231-260.

SECCHI, Leonardo. Políticas públicas: conceitos, esquemas de análise, casos práticos. 2. ed. São Paulo: Cengage Learning, 2013.

SILVEIRA, lara Maira da et al. Avaliação do efeito do Fundeb sobre o desempenho dos alunos do ensino médio no Brasil. Pesquisa e Planejamento Econômico, Brasília, DF, v. 47, n. 1, p. 7-44, 2017.

SOARES, Murilo Rodrigues da Cunha. Lei Kandir: breve histórico. Brasília, DF: Consultoria Legislativa da Câmara dos Deputados, 2007.

SOUZA, Celina. Políticas públicas: uma revisão da literatura. Sociologias, Porto Alegre, v. 8, n. 16, p. 20-45, 2006.

ZAPELINI, Marcello Beckert. Montagem de agenda no Comitê Itajaí: uma aplicação do modelo de Kingdon. Revista de Administração Contemporânea, Rio de Janeiro, v. 18, n. 6, p. 795-812, 2014.

Recebido em: 04.01.2019

Revisado em: 09.04.2019

Aprovado em: 05.06.2019

Joyce Santana Bernardo é graduada em ciências contábeis (2017) e mestre em administração (2019), pela Universidade Federal de Viçosa (UFV). Membro do Grupo de Pesquisa Políticas Públicas e Desenvolvimento Socioeconômico.

Luiz Antônio Abrantes é professor associado do Departamento de Administração e Contabilidade (DAD/UFV). Foi Pró-Reitor de Gestão de Pessoas da UFV (Gestão 06/201102/2015). Possui Graduação em administração (1984), em tecnólogo em cooperativismo (1979), mestrado em administração (1998) e doutorado em administração (2006) pela Universidade Federal de Lavras.

Fernanda Maria de Almeida possui graduação em ciências econômicas pela Universidade Federal de Viçosa (2007), mestrado (2009) e doutorado (2012) em economia aplicada também pela UFV. Atualmente é professora adjunto IV do Departamento de Administração e Contabilidade da mesma instituição.

Cristiana Tristão Rodrigues possui graduação em ciências econômicas (2007), mestrado (2010) e doutorado em economia aplicada (2014) pela Universidade Federal de Viçosa, com período de estágio de pesquisa na University of Califórnia, Riverside (2012). Atualmente é professora do Departamento de Economia na UFV. 